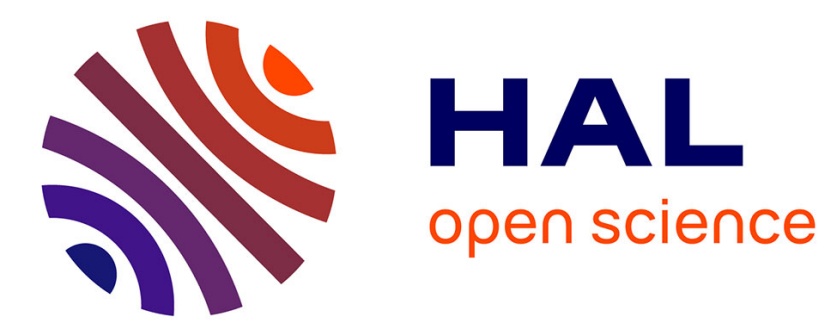

\title{
EXCHANGE MARKET PRESSURE: SOME CAVEATS IN EMPIRICAL APPLICATIONS
}

\author{
Simone Bertoli, Giampiero M. Gallo, Giorgio Ricchiuti
}

\section{To cite this version:}

Simone Bertoli, Giampiero M. Gallo, Giorgio Ricchiuti. EXCHANGE MARKET PRESSURE: SOME

CAVEATS IN EMPIRICAL APPLICATIONS. Applied Economics, 2008, 42 (19), pp.2435-2448. 10.1080/00036840701858059 . hal-00582240

\section{HAL Id: hal-00582240 \\ https://hal.science/hal-00582240}

Submitted on 1 Apr 2011

HAL is a multi-disciplinary open access archive for the deposit and dissemination of scientific research documents, whether they are published or not. The documents may come from teaching and research institutions in France or abroad, or from public or private research centers.
L'archive ouverte pluridisciplinaire HAL, est destinée au dépôt et à la diffusion de documents scientifiques de niveau recherche, publiés ou non, émanant des établissements d'enseignement et de recherche français ou étrangers, des laboratoires publics ou privés. 


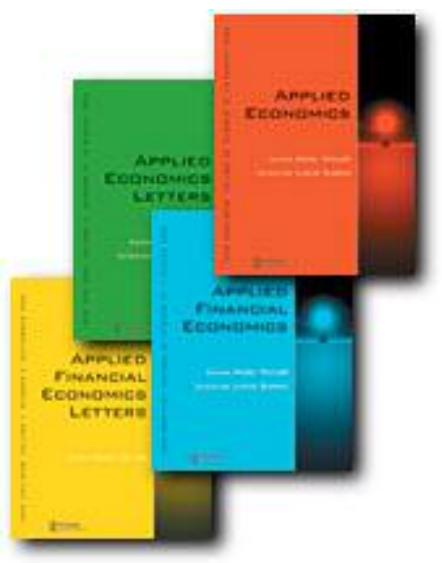

EXCHANGE MARKET PRESSURE: SOME CAVEATS IN EMPIRICAL APPLICATIONS

\begin{tabular}{|c|c|}
\hline Journal: & Applied Economics \\
\hline Manuscript ID: & APE-07-0308.R1 \\
\hline Journal Selection: & Applied Economics \\
\hline $\begin{array}{r}\text { Date Submitted by the } \\
\text { Author: }\end{array}$ & 05-Nov-2007 \\
\hline Complete List of Authors: & $\begin{array}{l}\text { Bertoli, Simone; Universita' degli Studi di Firenze, Dipartimento di } \\
\text { Scienze Economiche } \\
\text { Gallo, Giampiero; Universita' degli Studi di Firenze, Dipartimento di } \\
\text { Statistica "Giuseppe Parenti" } \\
\text { Ricchiuti, Giorgio; Universita' degli Studi di Firenze, Dipartimento di } \\
\text { Scienze Economiche }\end{array}$ \\
\hline JEL Code: & $\begin{array}{l}\text { F30 - General \&lt; F3 - International Finance \&lt; F - International } \\
\text { Economics }\end{array}$ \\
\hline Keywords: & $\begin{array}{l}\text { Currency Crises, Exchange Market Pressure, Emerging Countries, } \\
\text { Sensitivity Analysis, Speculative Attacks }\end{array}$ \\
\hline
\end{tabular}

\section{S ScholarONE" Manuscript Central}




\title{
EXCHANGE MARKET PRESSURE: SOME CAVEATS IN EMPIRICAL APPLICATIONS
}

\author{
Simone Bertoli \\ Dipartimento di Scienze Economiche \\ Università degli Studi di Firenze \\ via delle Pandette 9, 50127 Firenze, Italy \\ Giampiero M. Gallo \\ Dipartimento di Statistica "Giuseppe Parenti" \\ Università degli Studi di Firenze \\ viale G.B. Morgagni 59, 50134 Firenze, Italy \\ Giorgio Ricchiuti \\ Dipartimento di Scienze Economiche \\ Università degli Studi di Firenze \\ via delle Pandette 9, 50127 Firenze, Italy
}

\begin{abstract}
The Exchange Market Pressure (EMP) index, developed by Eichengreen et al. (1994), is widely used as a tool to signal whether pressure on a currency is softened or warded off through monetary authorities' interventions or, rather, a currency crisis has originated. In this paper we show how the index is sensitive to some assumptions behind the aggregation of the information available (exchange rates, interest rates and reserves), especially when emerging countries are involved. Specifically, we address the way exchange rate variations are computed and the impact of different definitions of the reserves, and we question the constancy of the weights adopted. These issues compound with the choice of a fixed threshold when crisis episodes are identified through the EMP index. As a result, one should exert caution in subsequent econometric analyses where a dependent binary variable is built to identify crisis periods.
\end{abstract}

Keywords: Currency Crises, Exchange Market Pressure, Emerging Countries, Sensitivity Analysis, Speculative Attacks

JEL Classification: F30

Running Title: Exchange Market Pressure: Some Caveats in Empirical Applications

Author for correspondence: Giampiero M. Gallo gallog@ds.unifi.it; Dipartimento di Statistica "Giuseppe Parenti" - Università degli Studi di Firenze - viale G.B. Morgagni 59, 50134 Firenze, Italy. 


\section{Introduction}

Currency crises in emerging and developing economies have been extensively analyzed in the literature with a variety of analytical tools proposed to identify crisis episodes. One of the indeces that are most widely adopted to signal the break up of a crisis is the Exchange Market Pressure, EMP hereafter, index introduced in a seminal paper by Girton and Roper (1977) to investigate independence of and interventionist stance by a Central Bank as a simple average of exchange rate changes and a foreign reserve depletion indicator. An extension was suggested by Eichengreen, Rose and Wyplosz (1994, henceforth ERW), adding the interest rate spread to the index, to describe possible monetary policy responses to a disequilibrium in the foreign exchange market (or, at least, a sudden surge in short term interest rates as a consequence of a tightening liquidity). Their index is an average weighted to equalize the different variability in the three variables.

To the best of our knowledge, ERW were the first to employ the EMP index as a basis for the analysis of exchange market behaviour for developed countries; when the EMP index passes over a threshold, excess pressure is flagged and a binary variable representing a crisis takes on a value of one for that period.

The EMP index is meant to capture depreciations but also the type of pressure on a currency (as would happen in the presence of depreciation expectations) which is softened or diverted through monetary authority interventions, and does not necessarily show up in the observed behaviour of nominal exchange rate dynamics (i.e. 'Peso Problem' type, Evans, 1996). In this view, crisis episodes occur even if speculative attacks are not successful.

Other papers have used the index (e.g. Eichengreen et al., 1996; Tudela, 2004), at times defined differently and with a different threshold to define a crisis. Some (e.g Sachs et al., 1996) limit themselves to a two-component version, which excludes interest rates. Kaminsky et al. (1998) and Kaminsky and Reinhart (1999) do the same but on the 
ground of data limitations, while Tanner (2001) has more theoretical objections to the insertion of what she sees as a response variable rather than an indicator.

This paper focuses on the methodological issues related to the use of the EMP index, as this has found a wide adoption in the literature on currency crises (Eichengreen et al., 1994, 1996; Kaminsky and Reinhart, 1998; Sachs et al., 1996; Tanner, 2001; Tudela, 2004). Without questioning the general theoretical framework within which the index is derived, we point out how seemingly harmless - and often hidden - choices required in the aggregation of the components of the index, may affect the results of subsequent empirical analysis. The EMP index may thus suffer from some weaknesses that cast doubts on its reliability as a basis for econometric analysis, especially when emerging countries are involved.

Several issues related to the adoption of the EMP index will be described in this paper. In the second section we discuss the way in which such an index is built, pointing out the statistical issues that emerge when multi-dimensional information is used. In the third section, we highlight the ad hoc assumptions introduced to build a binary crisis variable from the EMP index and the limits of a parametric definition of a crisis ${ }^{1}$. In a preliminary attempt to show how methodological choices do matter and are able to affect the econometric analysis on currency crises determinants, we employ data from a sample of 26 countries to show how the EMP index and the subsequent crisis indicator vary with different choices available. ${ }^{2}$ It is important to consider emerging countries alike, since the sensitivity of the EMP index proves to be directly related to the specific economic characteristics of a country, and for these countries data limitations are likely to be more binding. Finally, we discuss the issues surrounding the choice of a suitable country benchmark is not neutral, especially when emerging countries are involved. We

\footnotetext{
${ }^{1}$ We will not discuss the recent contributions by Haile and Pozo (2006) and Pontines and Siregar (2007), who avoid a parametric definition of the index using the Extreme Value Theory.

${ }^{2}$ See the Appendix for a description of the dataset.
} 
thus extend the discussion by Pontines and Siregar (2007) who have pointed out how replacing Japan to the US as the reference country, the EMP index for some East Asian currencies changes significantly, along with its capacity to signal the actual crisis episodes that hit this area in the late 1990s. Concluding remarks follow.

\section{The Exchange Market Pressure index}

The EMP index proposed by ERW is defined as:

$$
\mathrm{EMP}_{\mathrm{t}}=\alpha \Delta_{\%} \mathrm{e}_{\mathrm{t}}+\beta \Delta\left(\mathrm{i}_{\mathrm{t}}-\mathrm{i}_{\mathrm{t}}^{\mathrm{f}}\right)+\gamma \Delta\left(\mathrm{r}_{\mathrm{t}}^{\mathrm{f}}-\mathrm{r}_{\mathrm{t}}\right)
$$

that is a weighted average (with positive weights $\alpha, \beta$ and $\gamma$ ) of three variables: $\Delta_{\%} \mathrm{e}_{\mathrm{t}}$ is the percentage change in the nominal exchange rate against a reference currency, $\Delta\left(i_{t}-i_{t}^{f}\right)$ represents the variation in the spread between the domestic interest rate and the foreign interest rate $e^{3}$, and finally $\Delta\left(r_{t}^{f}-r_{t}\right)$ is the change in the spread between foreign reserves, relative to monetary base, abroad and at home. ${ }^{4}$ ERW employed quarterly data, while of most of the later applications use monthly data (Klaassen and Jager, 2006, being a notable exception), although such a data frequency could fail to capture episodes of short but intense speculative pressures on a currency. The EMP index can take values on the real line, with high positive values associated to a pressure on the domestic currency, as a combination of a nominal depreciation, a widening of the interest rate spread or a loss of foreign reserves. The insertion of the interest rate variable is not void of possible criticisms in that domestic interest rates may not be an

\footnotetext{
${ }^{3}$ The recent paper by Klaassen and Jager (2006) develops a model-free version of the EMP index, where the interest rates enter in levels rather than in first differences.

${ }^{4}$ The monetary base, defined either as $\mathrm{M}_{0}$ or $\mathrm{M}_{1}$, can be endogenous to the stock of foreign reserves in small open economies, so that the ratio of foreign reserves over the monetary base may fail to reveal the extent of direct interventions on the exchange market, as the two series move together (the Argentinean currency board of the 1990s represents an extreme example of such a dynamic), and - if data limitations are not binding - alternative standardization of the foreign reserves should be explored.
} 
intermediate policy target in all countries. In certain episodes, though, the change of interest rate spreads may signal a temporary liquidity tightening or some measure to avoid capital flights.

To avoid an overlapping of the issues that arise from the construction of the EMP index itself with those that emerge from its use as a crisis indicator, we will focus on the former in this section and devote the next section to the latter. Particularly, we will first discuss how three different issues influence the index: the choice of the weights; the use of logarithmic difference to approximate the percentage change of the exchange rate; the inclusion of gross or net foreign reserves. The EMP index turns out to be notably sensitive to seemingly minor choices, and this poses the problem of its fine tuning, as it is not always possible to rank possible alternatives, and different choices can be defended on different empirical or theoretical grounds.

\subsection{Weighting}

Since the three variables underlying the EMP index are usually characterized by different variability, their aggregation has to be conducted in such a way that prevents the most volatile component from dominating the whole index. The standard deviation of exchange rate variations and of the interest rate differential has a sample average, excluding Argentina, of approximately 1.5 and 900 times that of the foreign reserves movements. ERW suggest standardizing the three components, i.e. using the reciprocal of the country-specific standard deviation of the relative series as weights in [1], in order to equalize unconditional variances. This notwithstanding, financial time series are characterized by volatility clustering (Engle, 2004) and/or structural breaks, so that constant weights do not allow to adequately smooth changing variability. ${ }^{5}$

\footnotetext{
${ }^{5}$ Moreover, the presence of isolated peak values in a series drives down the weight that is attached to it, virtually reducing the dimensionality of the index; to provide a telling example, Argentina recorded a 7-digit interest rate change in 1990 in a desperate attempt to stop the fall of the peso.
} 
To illustrate the point, Figure 1 reports the monthly change in the nominal exchange rate of the Italian lira against the German mark and the changes in the Italian interest rate over the period 1970-1998. It shows the change in the volatility of the nominal exchange rate of the Italian lira against the German mark when Italy entered the Exchange Rate Mechanism of the European Monetary System and when it quit it in September 1992; by the same token, domestic interest rates exhibit sudden changes in volatility as well, occurring at times in correspondence to a successful deflection of exchange rate pressure. Thus, a standardization of the index components through their respective sample variances implies that the evolution of the series fails to convey much information to the index during periods of low volatility.

\section{FIGURE 1 ABOUT HERE}

The volatility clustering of the different series could be consistent with changes over time of the preferred instruments that are chosen by the monetary authorities in order to deal with pressure on the domestic currency. ${ }^{6}$ A separate phenomenon requiring some sort of time varying weights involves countries which have experienced hyperinflation episodes, which translate into wild swings in some nominal aggregates. ${ }^{7}$

Possible attempts to overcome the tight limits of fixed weights rely either on moving standard deviations or to compute sample variances over sub-intervals of the time frame of the analysis, i.e. five or ten years standard deviations. Further suggestions include, as

\footnotetext{
${ }^{6}$ Li et al. (2006) argue that"all three components are considered policy variables whose volatilities reflect at least in part the authority's preferences for policy strategies [...] Ideally, one should strip out the reserve volatility caused by the free market and retain the policy part of the volatility."

${ }^{7}$ Pontines and Siregar (2007) replace the nominal with the real exchange rate during the hyperinflation episodes, but this approach does not address the impact of hyperinflation on the domestic nominal interest rate, and it introduces a further discretionary choice in the construction of the EMP index, namely the identification of hyperinflation periods.
} 
in Haile and Pozo (2006), the possibility of estimating GARCH-type conditional standard deviations, when time series properties are consistent with volatility clustering.

\subsection{Exchange rate variations}

The first component of the EMP index that appears in [1] is given by the rate of change of the nominal exchange rate of the domestic currency against an anchor currency over the period of reference. With a few exceptions, the method used to compute the rate of variation is left unspecified. ${ }^{8}$ The logarithmic difference provides a good approximation of the rate of change around zero, and hence its use is rather immaterial as far as this choice refers to developed countries. But the structural differences that characterize the distribution of the monthly rate of variations of the nominal value of developed and emerging countries' currencies imply that the method of computation does matter when emerging countries are involved. An enduring tendency towards depreciation, coupled with periods of sudden and sharp loss of value, is mostly found when looking at the evolution of the nominal exchange rate between an emerging country's and a developed country's currency in the long run. This trend may be due to several underlying factors, most notably the existence of a positive inflation differential with the reference country. On the other hand, the nominal exchange rate between a pair of developed countries tends often to be fairly stable if a sufficiently long time span is considered, and monthly variations tend to be smaller in absolute value.

To illustrate this point, Figure 2 shows the distribution of the monthly rate of variation of nominal exchange rate with the US dollar for the Uruguayan peso and the British pound. The distribution of the monthly rate of change of the exchange rate between the pound and the US dollar has a mean of 0.13 percent, and it is fairly symmetric around zero. On the other hand, the distribution of the rate of change of the Uruguayan peso

\footnotetext{
${ }^{8}$ Eichengreen et al. (1996) employ logarithmic differences, while Pontines and Siregar (2007) use the exact formula.
} 
against the US dollar has a mean equal to 5.28 percent; it is asymmetric, with 94.92 percent of the observations signalling depreciation, and with a thicker upper tail. For the pound, just one observation lies above 10 percent (September 1992), i.e. outside the range that is shown in the plot, while for the peso we find ten observations above that threshold.

\section{FIGURE 2 ABOUT HERE}

The relevance of the method used to compute the variation of the exchange rate is twofold: first, logs provide a poor approximation of the rate of change when this is large; second, and most notably, the logarithmic approximation determines a significantly lower variance of the sample distribution of the rate of variation of the nominal exchange rate for most emerging countries. A priori, it is not possible to predict whether the use of logarithms will generate a distribution with a higher or smaller variance, as the log function is a contraction mapping on the domain $(1,+\infty)$ and an expansion mapping in the domain $(0,1) .{ }^{9}$ But, if the sample values of the rate of change lie disproportionately above or below zero, the use of the logarithmic approximation influences the standard deviation of the transformed values in a predictable way. For the Uruguayan peso, the standard deviation of its monthly rate of change is 0.47 when the rate is computed with the exact formula and 0.17 when logs are applied. For the British pound we need a four-digit precision to appreciate a difference between the two methods, as the standard deviation decreases from 0.0242 to 0.0241 . To strengthen this point, Table 1 shows the two sets of values of standard deviations for the sample countries. The difference is negligible for developed countries, while it shows up as systematic for emerging countries. The most notable differences are reported for Latin American countries, many of which experienced hyperinflation in the 1980s and in the

\footnotetext{
${ }^{9}$ See Bertoli et al. (2006) for a formal demonstration of the impact of a contraction mapping over the variance of a series.
} 
1990s, and this caused sharp and prolonged depreciations of their currencies. For Chile, Peru and Uruguay, the use of logarithms reduces the standard deviation of the exchange rate variable to less than half of the value that is found when rates of variation are computed with the exact formula.

\section{TABLE 1 ABOUT HERE}

\subsection{International reserves}

The inclusion of international reserves in the EMP index is intended to capture those episodes of speculative pressure driving the central bank to intervene on the foreign exchange spot market in defence of its currency. However, just a part of a central bank's operations translate into a variation in the level of international reserves; a central bank can attempt to defend its currency by drawing on stand-by credits or through off-balance-sheet transactions, as forward market interventions, thus not committing any of its foreign assets on the spot market. Thailand's gross international reserves had remained fairly stable in the first six months of 1997, but the severe currency crisis of July 2 occurred when it became apparent that all of its foreign assets had already been committed on the forward market (Stiglitz, 2002). Similarly, Goldstein (2001) argues that "Korea's lending of reserves to commercial banks meant that the figures on gross reserves conveyed a misleading impression of the authorities' usable liquid assets", so that these episodes clearly show the limitations of inferring the magnitude of monetary authorities' interventions on foreign exchange markets from variations in the level of reserves, but this remains the only feasible option as central banks do not give notice of their off-balance-sheet operations. ${ }^{10}$

\footnotetext{
${ }^{10}$ Other papers (Goldstein and Hawkins, 1998; Lee, 2001) mention the significant transfer of foreign currency from the Central Bank to the South Korean banking system, but do not quantify the dimension of these off-balance-sheet operations, and Goldstein and Hawkins (1998) also resort to an extremely
} 
Data availability is a strong constraint, at times, in what concerns a central bank's foreign assets since they may be reported either net or gross of international liabilities. Choosing one or the other, or even mixing the two measures in a cross country context is by no means neutral as differences can be rather substantial and the movements of gross and net reserves sometimes can convey conflicting information, thus leading to different perceptions of the pressure a currency is subject to. The inclusion of gross reserves may be preferable if one is interested in liquidity crises, while net reserves may be better suited for studies on the determinants of solvency crises.

If the choice between gross and net reserves is not guided by a clear cut definition of financial crisis, this should be influenced by the need to treat in a consistent way the countries that are included in the sample. Countries may differ with respect to the frequency with which they activate credit lines in foreign currencies, and the same country can change over time its reliance on off-balance-sheet operations to face speculative pressure on its currency. When gross reserves are chosen as a component of the EMP index, the index will reveal, ceteris paribus, a softer pressure on a currency whose exchange rate is backed by the activation of credit lines in foreign currencies. ${ }^{11}$ If the monetary authorities can draw resources from these credit lines, they can face speculative pressure on their currency without having to deplete their gross foreign assets. In particular, countries can activate a stand-by arrangement or a loan with the International Monetary Fund when they experience Balance of Payments need. The amount of Fund credit and loans outstanding is reported for each member country by the IFS, and this series - that is published on a monthly basis by the IMF - can be used

cautionary description of these interventions, as they observe "it has been suggested that some of the Korean international reserves were not usable as they had been lent to banks" (emphasis added).

${ }^{11}$ The choice between net and gross reserves implies a change in the weights, if the weights of the three components of the index are chosen so to equalize their conditional variability. However, from our sample it does not emerge any systematic difference in the volatility of gross or net reserves, and changes in the weights are rather small. 
to account for a specific form of international liabilities that is extremely significant for emerging countries. ${ }^{12}$

To provide a concrete example, Figure 3 shows the evolution of international reserves both gross and net of the liabilities towards the IMF - for Argentina over the period 1993-2002 and for Italy in the 1970s. The figure for Argentina reveals a prolonged period of Fund assistance: focussing on the crisis of 2001 shows that the pattern followed by net reserves signals a much greater incidence of the crisis than what be inferred looking at the evolution of gross reserves. The inclusion of either series in the EMP index will thus provide a different picture of the recent Argentinean crisis.

\section{FIGURE 3 ABOUT HERE}

When international reserves are considered net of monetary authorities' liabilities towards the IMF, this allows for the inclusion in the same sample of countries that receive significant financial assistance from the IMF before or in the aftermath of a crisis, and countries that do not. The different paths followed by Malaysia and South Korea in 1997, after the crisis had broken out in Thailand, constitute a good example of the need for a consistent treatment of international reserves variations for countries that have to be included in the same sample. As it is well known, Malaysia pursued its own

\footnotetext{
12 This series does not include the undrawn balance of a stand-by agreement with the IMF; Mussa and Savastano (2001) point out that "more than a third of all Fund arrangements approved between 1973 and 1997 ended with a disbursement of less than an half of the initially agreed support. [...] Mainly these were cases where the program went off track because policies deviated significantly from those agreed with the IMF and subsequent negotiations failed to reach agreement on a modified program.". This reflects the strong conditionality of the IMF credit, that suggests that the undrawn balance of a stand-by agreement should not be considered as resources that can be freely disposed of by a central bank to defend its currency.
} 
adjustment program, introducing temporary restrictions to capital movements, without drawing resources from the IMF. On the other hand, South Korea received 11 billions of US dollars in December 1997, and its debt towards the IMF kept on rising till October 1998, when it reached 18.7 billions, well above 1,600 percent of its Fund quota. The resources South Korea received from the Fund in December 1997 amounted to more than an half of its gross international reserves.

If reserves are considered gross of central bank's liabilities towards the IMF, then there is the risk of underestimating the pressure a currency is subject to, when its reserves are supported by large inflows of Fund credit. Even though this point is clearly relevant for emerging countries, it should be noted that if the time span of the analysis covers the 1970s, the need to account for liabilities towards the Fund concerns developed countries as well, as in Figure 3. In the 1970s and early 1980s, several European countries received credit from the IMF, often well above their respective Fund quotas. For example, in January 1976, Italian liabilities towards the IMF were almost three times the level of Italian gross foreign reserves, and thus its net reserves were negative.

\section{EMP-based definitions of currency crises}

A widely adopted approach to the analysis of currency crises entails the division of sample observations among crisis episodes and periods of tranquillity. This requires an identification rule: the crises could be defined either as the transition between two different exchange rate regimes, as the flotation of a pegged exchange rate, or as exceptional movements of the nominal exchange rate (Frankel and Rose, 1996) or of a broader index of excess demand for foreign currency, as the EMP index ${ }^{13}$.

In ERW and Kaminsky and Reinhart (1999) a crisis is signalled when the EMP index is above a critical threshold defined as a function of the (country-specific) sample mean

\footnotetext{
${ }^{13}$ See Bubula and Otker-Robe (2003) for an overview of identification rules proposed in the literature.
} 
and standard deviation of the index. Hence, their index (IC) reveals a currency crisis in period $\mathrm{t}$ when the standardized EMP index crosses a threshold $\tau$ :

$$
\left\{\begin{array}{l}
I C_{t}=1 \text { if } \frac{\mathrm{EMP}_{\mathrm{t}}-\mu_{\mathrm{EMP}}}{\sigma_{\mathrm{EMP}}}>\tau \\
I C_{t}=0 \text { if } \frac{\mathrm{EMP}_{\mathrm{t}}-\mu_{\mathrm{EMP}}}{\sigma_{\mathrm{EMP}}} \leq \tau
\end{array}\right.
$$

The definition of the critical threshold is a discretional "rule of thumb" for the identification of a currency crisis, and the crisis set, i.e. the set of observations that are identified as crisis episodes, is clearly sensitive to the choice of the width of the tranquillity band. ERW set $\tau$ equal to 1.5, while Kaminsky et al. (1998) and Kaminsky and Reinhart (1999) adopt a critical value of 3. These thresholds seem to be inspired by some sort of parametric assumption on the distribution of the standardized EMP index. As noted by Haile and Pozo (2006) and by Pontines and Siregar (2007) this may be a strong limitation of the procedure as non-normality is to be expected. The crisis set is thus dependent on the adopted identification rule, and this suggests the opportunity to gather some indications from the previous discussion on the construction of the EMP index and undertake some sensitivity analysis on the definition of a crisis.

Adopting the definition of the EMP index and the crisis identification rule from ERW, ${ }^{14}$ we can compare the effects of alternative specifications for the items discussed above (exchange rate computation, gross or net foreign reserves, weighting). A simple index of the distance between outcomes will help us in appraising divergence of the results.

\subsection{Sensitivity analysis for the fine tuning issues}

\footnotetext{
14 The rate of variation of the exchange rate is computed with the log approximation, international reserves are taken gross of any liabilities, Germany is the reference country for all European countries except the United Kingdom while the US is the reference country for the remaining countries. The weights of the three components are time invariant, the average and standard deviation of the EMP index are computed over the whole sample and finally $\tau$. is set equal to 1.5
} 
Actual episodes of currency crisis - as the ERM crisis of 1992, the Tequila crisis of 1994, the Asian Flu of 1997 or the most recent Argentinean crisis - may seem to represent a natural benchmark against which the empirical relevance of fine tuning issues concerning the EMP index could be assessed. Still, these episodes are actually not well suited to gauge the relevance of these issues, and the reason is that these crises determined actual currency crashes, i.e. large upward variations in the nominal exchange rate, so that hardly any variation in the underlying choices can influence the capacity of the EMP index to detect these episodes. EMP indices have been introduced in the literature to identify those episodes of intense speculative pressure that do not determine currency crashes, as "crises, devaluations and flotations are overlapping but distinct sets of turbulent foreign exchange market events." (Eichengreen et al., 1995). Bubula and Otker-Robe (2003) argue that "it is important to capture both the episodes that end up with a sharp change in the exchange rate, as well as those successfully withstood by the authorities", and modifications in the construction of the EMP index can be expected to have a larger impact on the latter than on the former type of episodes. We admit that this benchmark is more elusive than the one represented by notorious currency crashes, but we maintain that this is more coherent with the rationale behind the introduction of EMP indices, that is a dissatisfaction with crisis definitions based solely on exchange rate movements.

Let us consider the classification of each period in the sample as a crisis or a tranquil period according to the specification adopted, and let us define a country-specific divergence index Divi,j, between two different specifications $i$ and $\mathrm{j}$ :

$\operatorname{Div}_{\mathrm{i}, \mathrm{j}}=1-\frac{\#\left(\mathrm{IC}_{\mathrm{i}} \cap \mathrm{IC}_{\mathrm{j}}\right)}{\#\left(\mathrm{IC}_{\mathrm{i}} \cup \mathrm{IC} \mathrm{C}_{\mathrm{j}}\right)}$

that is, 1 minus the ratio of the number of periods classified as a crisis by both specifications to the total number of crises identified by either specification. This measure ranges between 0 (perfect coincidence of the two crisis sets) and 1 (no common identification). Table 2 displays the extent of divergence when a) the rate of 
exchange rate variation is computed exactly ( 0.01 average divergence for developed countries versus 0.10 for emerging countries), b) the reserves are taken net of liabilities towards the IMF (0.01 versus 0.16$)$, and c) the three components are standardized through 11-year moving standard deviations (0.24 versus 0.34$)$.

Looking at developed countries, it is apparent that the way exchange rates and reserves are computed is irrelevant: the logarithmic difference provides a close approximation of the actual rate of variation of the exchange rate of their currencies, and the use of either gross or of net reserves in ERW does not significantly affect the identification of a crisis period. ${ }^{15}$ This is not true for emerging countries: hyperinflation episodes in Latin America imply that logarithms provide a poor approximation of the sudden and wide depreciations of the domestic currencies they induced. Moreover, the relevance of the choice between either gross or net reserves extends to Asian countries as well, especially to Indonesia, South Korea and Thailand, as they draw heavily on IMF credit. As noted above, the largest overall changes come from time-varying weights which affect developed countries as well with highest values for Sweden (0.44), Italy (0.30) and the United Kingdom (0.27).

\section{TABLE 2 ABOUT HERE}

\subsection{Sensitivity Analysis relative to the Threshold}

The choice of the threshold is an arbitrary "rule of thumb", aimed at detecting 'enough' crises: as the threshold increases, the crises detected are fewer and necessarily the worst ones. Since the outcome of this analysis is to classify periods, it is necessary to investigate what type of results would be ensuing. Table 3 reports the percent of periods identified as a crisis for each country as a function of the threshold $\tau$. Several features of

\footnotetext{
${ }^{15}$ A minor exception is United Kingdom, that, as noted earlier, recorded periods in the 1970s where its net reserves were negative.
} 
this table are worth pointing out: first and foremost, the inadequacy of the same parametric distribution as a reference distribution for the standardized EMP index (the first row reports the reference values of the probability to the right of the corresponding threshold value under a normal distribution).

\section{TABLE 3 ABOUT HERE}

Standardization is not enough to induce normality (especially for emerging countries): most empirical distributions are positively skewed (20 out of the 25 countries), and the kurtosis is above 3 for all countries. If one chooses a fixed threshold, Table 3 says that for lower levels of $\tau$, a larger number of crises are signalled for developed than for emerging countries, while the situation reverses as $\tau$ increases (pointing to fatter tails for the emerging countries). With the value adopted by ERW, $\tau=1.5$, for example, the percentage of periods identified as crises for developed and emerging countries is 5.88 and 3.92 respectively, while when $\tau=3.0$ we find 1.29 for developed and 1.48 percent for emerging countries. Even the ordering of countries within the sample relative to the number of crises detected changes with the threshold: Germany passes from the 3rd to the 23rd place when $\tau$ increases from 1.5 to 2.0; United Kingdom has the second highest incidence when the threshold is set at 1.5 , while it has the second lowest when this moves to 3.0. The reverse happens to Mexico and Argentina.

The rate at which the number of crises detected for developed countries decreases with $\tau$ greatly outpaces the corresponding rate for emerging countries. This suggests that episodes of crisis detected for emerging countries correspond to a higher value of the (standardized) EMP index and, in a way, they are less sensitive to a fixed $\tau$ when this is large. This leads to the seemingly counterintuitive finding that emerging countries tend to have a smaller number of crises when $\tau=1.5$. The empirical evidence provided shows that the distributions of the EMP indices are quite different from one another and calls 
into question the very definition of a crisis: it sounds less appropriate to use the same threshold to define a crisis for a country than it is to refer to country-specific characteristics.

Adopting a sort of Value at Risk framework, we may define as extreme periods worthy of attention those episodes which occur with at most a certain probability. The extension of a parametric EMP-based identification rule to a set of diverse countries suggests that, as already noted by Pontines and Siregar (2007), we need to move towards alternative identifications rule that can better handle the sample distribution of the index. As noted, Table 2 provides an illustrative example of how the binary crisis variable is sensitive to one of the three fine tuning issues that have been discussed in the previous subsections. But, to the best of our knowledge, no empirical study so far has tested the robustness of its results to changing definitions of crisis or to different choices related to the underlying index. Table 4 displays the $95^{\text {th }}$ percentiles of the sample distributions of the standardized EMP index built according to eight different specifications as before.

\section{TABLE 4 ABOUT HERE}

There are noticeable variations both by column (across countries) and by row (across specifications), although the averages by country subgroup are fairly stable, roughly 1.6 for developed countries and 1.3 emerging countries. Across countries we can mention a widespread range, e.g. in the first column between 1.38 for Japan and 1.98 for Denmark, and between 1.11 for Thailand and 1.63 for Mexico. Within countries the ranges are spread as well: Argentina and South Korea, for example, have 95th percentiles in the ranges $1.25-1.64$ and $1.16-1.48$ respectively.

To complete the analysis, Table 5 displays the $99^{\text {th }}$ percentiles of the sample distributions of the standardized EMP index. If the threshold were to be set at a higher 
value so that only 1 percent of the periods is classified as a crisis episode, the values increase considerably and more so for emerging countries than for developed ones (on average roughly 3.82 and 3.35 respectively). The variability across countries and specifications is maintained as well.

\section{TABLE 5 ABOUT HERE}

\section{The Reference Country}

In the construction of the EMP index, a country is selected as a suitable benchmark in order to avoid reading the switches in the relevant domestic data driven by changes in the conditions prevailing on international markets as signals of pressure on the exchange market. The obvious benchmark for European countries has been Germany while the US is the reference country for the other OECD countries (see ERW). However when emerging countries are involved, the choice is not as clear-cut. While Pontines and Siregar (2007) were the first to raise the point that the anchor currency may have a bearing on the sensitivity of the crisis index, their findings reveal just a specific case of a systematic impact of any shift in the reference country, as shown in the following Proposition (proof of which is available in Bertoli et al., 2006):

Proposition- Given three countries, $\mathrm{A}, \mathrm{B}$ and $\mathrm{C}$, let $\mathrm{EMP}_{\mathrm{t}}^{\mathrm{AB}}$ denote the EMP index for country A at time $t$ with the reference country $B$. If the variations of the nominal exchange rate are computed as logarithmic differences and the same weight is attached to each component of the EMP indices in [4], then we have an add-up relationship:

$$
\mathrm{EMP}_{\mathrm{t}}^{\mathrm{AC}}=\mathrm{EMP}_{\mathrm{t}}^{\mathrm{AB}}+\mathrm{EMP}_{\mathrm{t}}^{\mathrm{BC}}
$$

Under the hypothesis introduced in the Proposition, the shift in the reference country is equivalent to adding the EMP index between the two reference countries to the original index. Although the weights differ across countries in most empirical applications, the 
relationship described in [4] can be shown to provide a good approximation of the impact of a shift in the reference country even when the hypothesis of identical sets of weights is violated ${ }^{16}$.

Table 6 displays the changes in six Asian countries' crisis sets when Japan replaces the US in the role of reference country. The first (respectively, second) letter in the label of each column reflects whether the period is identified as a crisis, c, or tranquil, n, when Japan (the US) is the reference country.

\section{TABLE 6 ABOUT HERE}

The extent of divergence of the two crisis sets is remarkable: on average the change in the reference country (from the US to Japan) determines a degree of divergence computed as in [4] - equal to 0.56 between the two alternative crisis identification rules. In the case of Singapore, the two rules agree just in 5 out of the 34 periods that are identified as crisis by either of the two. For Malaysia and Thailand, the degree of divergence amounts to 0.65 and 0.53 respectively. The evidence provided thus confirms and extends the results advanced by Pontines and Siregar (2007), and suggests that the choice of the appropriate anchor currency for East Asian countries is likely to have a significant bearing on the analysis of currency crisis determinants.

\section{Concluding Remarks}

This paper provides a detailed description of the issues that arise from the adoption of the EMP index to study currency crises. The EMP index represents a step forward from previous studies that relied on exchange rate movements alone to identify speculative pressures on a currency. Particularly, it is widely used to study currency crises since it allows to signal those pressures on a currency that are softened or warded off through

\footnotetext{
${ }^{16}$ For brevity's sake we do not include this result (achieved using data from the seven Asian countries) in this paper; the estimates are available upon request from the authors.
} 
monetary authorities' interventions, thus avoiding a bias in the selection of crisis episodes due to the missing observation of unsuccessful speculative attacks, as it would happen if the selection rested merely on nominal exchange rate movements. However, it presents some problematic characteristics that deserve a thorough scrutiny.

Three fine tuning issues related to the index construction were reported, regarding: the weighting scheme adopted to combine the three underlying variables, the suitability of logarithmic differences to compute the percentage change of the exchange rate, and the theoretical issues that arise from the inclusion of net rather than gross reserves. Whenever possible, we have indicated possible alternatives, or the criteria that should inform the choice. Since the EMP index, as we have rather extensively argued and showed, is notably sensitive to these seemingly minor choices, these should be explicitly stated and described, and the robustness of the results of following econometric analysis should be carefully assessed. Furthermore, we have shown that differences in the structure of the economic system, such as those observed in emerging countries; strongly affect the consistency of the assumptions and, consequently, the results that can be achieved. Even the widely accepted use of logarithms can quite significantly distort the EMP index for these countries. This simple example is revealing of how an analytical tool that has been first created for OECD countries is not well suited for a straightforward application to emerging countries. In addition evidence provided confirms that, since reference country may have a significant impact the analysis, a preliminary study is needed to evaluate the appropriate anchor.

In synthesis, an alternative EMP-based definition of crisis has to be still countryspecific, but at the same time it has to satisfy two additional properties that do not belong to previous definitions. The properties that characterize the proposed definition are: 1) spatial relativity; 2) temporal relativity; 3) the classification of past observations does not depend on future data. 
While the first property is shared by ERW definition, the other two represent an attempt to overcome two weaknesses of their crisis indicator. Indeed, the time invariance of the crisis threshold can constitute an undesirable feature if the EMP index presents some clusters of high volatility. These drive up the threshold, and render the index insensitive to those speculative pressures that occur during period of low volatility. Thus, instead of taking sample mean and standard deviation over the whole sample, moving average and standard deviation can be employed, computed over a period that is long enough to detect structural breaks in volatility from periods of increasing pressure. However, this possible approach suffers from two main shortcomings: first, it shrinks the sample size and information is lost, as a centred moving average is a function of lags and leads and thus missing values are generated for the initial and final observations. Second, it is not consistent with the third property, as the classification of an observation is still dependent on future values.

At least two reasons can be advanced to justify the desirability of the independence of the identification of past observations from future data, a property that is satisfied by the definitions employed by Frankel and Rose (1996) and Kumar et al. (2003). First, an instrumental one, as the dependence of past identifications on future observations gives rise to a never-ending process of data revision, while a second reason relates to the analytical perspective from which currency crises are observed. While subsequent data are useful to put the conditions prevailing on the exchange market in an historical perspective, these should not be relevant in a more policy-oriented approach, that is more interested on the evaluation that economic agents give of current events.

This paper suggests that existing EMP-based crisis indicators may not be well suited for the study of currency crises in emerging countries, as they lead to a questionable selection of crisis episodes, and suggests that emerging countries are much less crisis-prone that developed countries. In order to test the actual relevance of this intuition, we intend to deepen this research in two complementary directions: first, to 
understand punctually and clarify the differences between ERW index of crises and our proposed crisis selection rules; second, to build different crisis sets according to diverging crisis selection rule, and to employ these sets as explanatory variables in an econometric analysis - either a logit or a probit model - on currency crises determinants.

\section{Acknowledgements}

We would like to thank Christian Brownlees, Fabrizio Cipollini, Marco J. Lombardi, Angela Parenti, Margherita Velucchi, the Editor Mark Taylor and three anonymous referees for their helpful comments and suggestions. The usual disclaimer apply.

\section{References}

Bertoli, S., G. M. Gallo and G. Ricchiuti (2006) Exchange Market Pressure: some caveats in empirical application, Working Paper No. 2006/17, Department of Statistics, University of Florence.

Bubula, A. and I. Otker-Robe (2003) Are Pegged and Intermediate Exchange Rate Regimes More Crisis prone?, IMF Working Paper No. 03/223.

Eichengreen, B., A. K. Rose and C. Wyplosz (1996) Contagious Currency Crises, CEPR Discussion Paper No. 1453.

Eichengreen, B., A. K. Rose, and C. Wyplosz (1994) Speculative Attacks on Pegged Exchange Rates: An Empirical Exploration with Special Reference to the European Monetary System, NBER Working Paper No.4898.

Eichengreen, B., A. K. Rose, C. Wyplosz, B. Dumas and A. Weber (1995) Exchange Market Mayhem: The Antecedents and Aftermath of Speculative Attacks, Economic Policy, 10, 249-312.

Engle R. (2004) Risk and Volatility: Econometric Models and Financial Practice, The American Economic Review, 94, 405-20.

Evans, M. D. D. (1996) Peso problems: their theoretical and empirical implications, in Statistical Methods in Finance (eds.) G.S. Maddala and C.R. Rao, North-Holland, Amsterdam, pp. 613-46.

Fratzscher, M. (2003) On Currency Crises and Contagion, International Journal of Finance and Economics, 8, 109-29.

Frankel, J. A. and A.K. Rose (1996) Currency Crashes in Emerging Markets: An Empirical Treatment, Journal of International Economics, 41, 351-66. 
Girton, D. and L. Roper (1977) A Monetary Model of Exchange Market Pressure Applied to the Post-war Canadian Experience, The American Economic Review, 67, 537-48.

Goldstein, M. and J. Hawkins (1998) The Origin of the Asian Financial Turmoil, Research Discussion Paper No. 9805, the Reserve Bank of Australia.

Goldstein, M. (2001) The Asian Financial Crisis: Origin, Policy Prescriptions and Lessons, Journal of African Economies, 10, AERC Supplement 1, 72-103.

Haile, F. D. and S. Pozo (2006) Exchange Rate Regimes and Currency Crises: an Evaluation using Extreme Value Theory, Review of International Economics, 14, 554-70.

Kaminsky, G.L. (2003) Varieties of Currency Crises, NBER Working Paper No. 10193.

Kaminsky, G.L., S. Lizondo and C. Reinhart (1998), Leading Indicators of Currency Crises, IMF Staff Papers, 5, 1-48.

Kaminsky, G.L. and C. Reinhart (1999) The Twin Crises: The Causes of Banking and Balance of Payments Problems, The American Economic Review, 89, 473-500.

Kaminsky, G.L. and C. Reinhart (1998) Financial Crises in Asia and Latin America: Then and Now, The American Economic Review, 88, Papers and Proceedings of the Hundred and Tenth Annual Meeting of the American Economic Association, 444-8.

Kumar, M, U. Moorthy, and W. Perraudin (2003) Predicting emerging market currency crashes, Journal of Empirical Finance, 10, 427-54.

Klaassen, F. and H. Jager (2006) Model-free Measurement of Exchange Market Pressure, Discussion Paper No. 2006-112/2, the Tinbergen Institute.

Lee, H.-H. (2001) The IMF rescue programme in Korea: What Went Wrong, Journal of Korean Economy, 2, 69-86.

Li, J., R. S. Rajan and T. Willet (2006) Measuring Currency Crises Using Exchange Market Pressure Indices: The Imprecision of Precision Weights, mimeo, the Central University of Finance, Economics and Business, Beijing.

Mussa, M. and M. Savastano (1999) The IMF Approach to Economic Stabilization, IMF Working Paper No. 99/104.

Pontines, V. and R. Siregar (2007) The Yen, the US dollar, and the trade weighted basket of currencies: Does the choice of anchor currencies matter in identifying incidences of speculative attacks?, Japan and the World Economy, 19, 214-35.

Sachs, J., A. Tornell and A. Velasco (1996) Financial Crises in Emerging Markets: The Lessons from 1995, NBER Working Paper No. 5576.

Stiglitz, J. E. (2002) Globalisation and its Discontents, Penguin Books, London.

Tanner, E. (2001) Exchange Market Pressure and Monetary Policy: Asia and Latin America in the 1990s, IMF Staff Papers, 47, 311-33. 
Tudela, M.M. (2004) Explaining Currency Crises: A Duration Model Approach, Journal of International Money and Finance, 23, 799-816.

\section{Appendix - Outline of the dataset}

We have collected monthly data for a sample of 26 countries over the period 1970-2002. The sample is made up of ten European countries (Denmark, Finland, France, Germany, Italy, the Netherlands, Spain, Sweden, Turkey and the United Kingdom), seven Latin American (Argentina, Chile, Colombia, Mexico, Peru, Uruguay and Venezuela), seven Asian (Indonesia, Japan, Malaysia, Philippines, Singapore, South Korea and Thailand), the United States of America and Canada. Data limitations influenced the choice of the sample countries, and thus our sample is not meant not be representative of either developed or emerging economies. For the European countries that have adopted the euro, the series are interrupted in December 1998.

The data source is given by the International Financial Statistics, IFS, published monthly by the International Monetary Fund. The data include:

- $\quad$ monthly average of the nominal exchange rates, line rf IFS;

- $\quad$ short term deposit interest rate, line $60 \mathrm{~b}$ IFS $;^{17}$

- $\quad$ total reserves excluding gold, line 11.d IFS;

- $\quad$ restricted money base, line 34 IFS;

- $\quad$ IMF credit and loans outstanding, line 2tl IFS.

If not otherwise specified, the EMP index is computed - in accordance with ERW under the following default choices: the US is the reference country, the series are weighted by the reciprocal of their sample standard deviation, exchange rate variations are computed as logarithmic differences, reserves are considered gross of the liabilities towards the IMF. A crisis is detected whenever the EMP is above its mean plus 1.5 times its standard deviation.

\footnotetext{
${ }^{17}$ If unavailable, we have the three months lending rate; for the US, we have used the Treasury Bill Rate.
} 
Figure 1. Monthly rates of change in the nominal exchange rate of the Italian Lira against the German Mark (upper panel) and in the Italian nominal interest rate (lower panel)
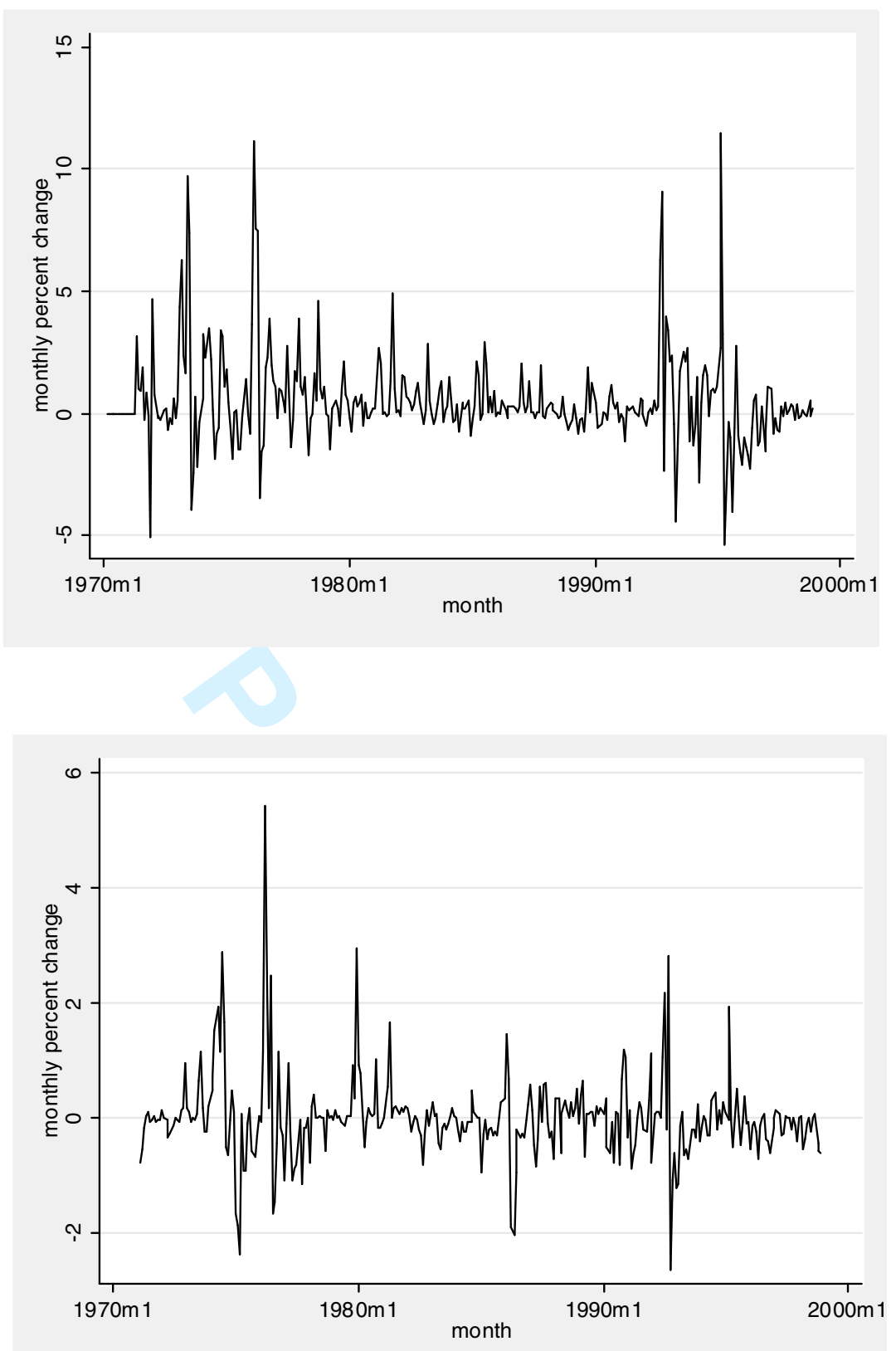
Figure 2. Distribution of monthly rate of change of nominal exchange rate against the US Dollar for the Uruguayan Peso (upper panel) and the British Pound (lower panel), 1970-2002
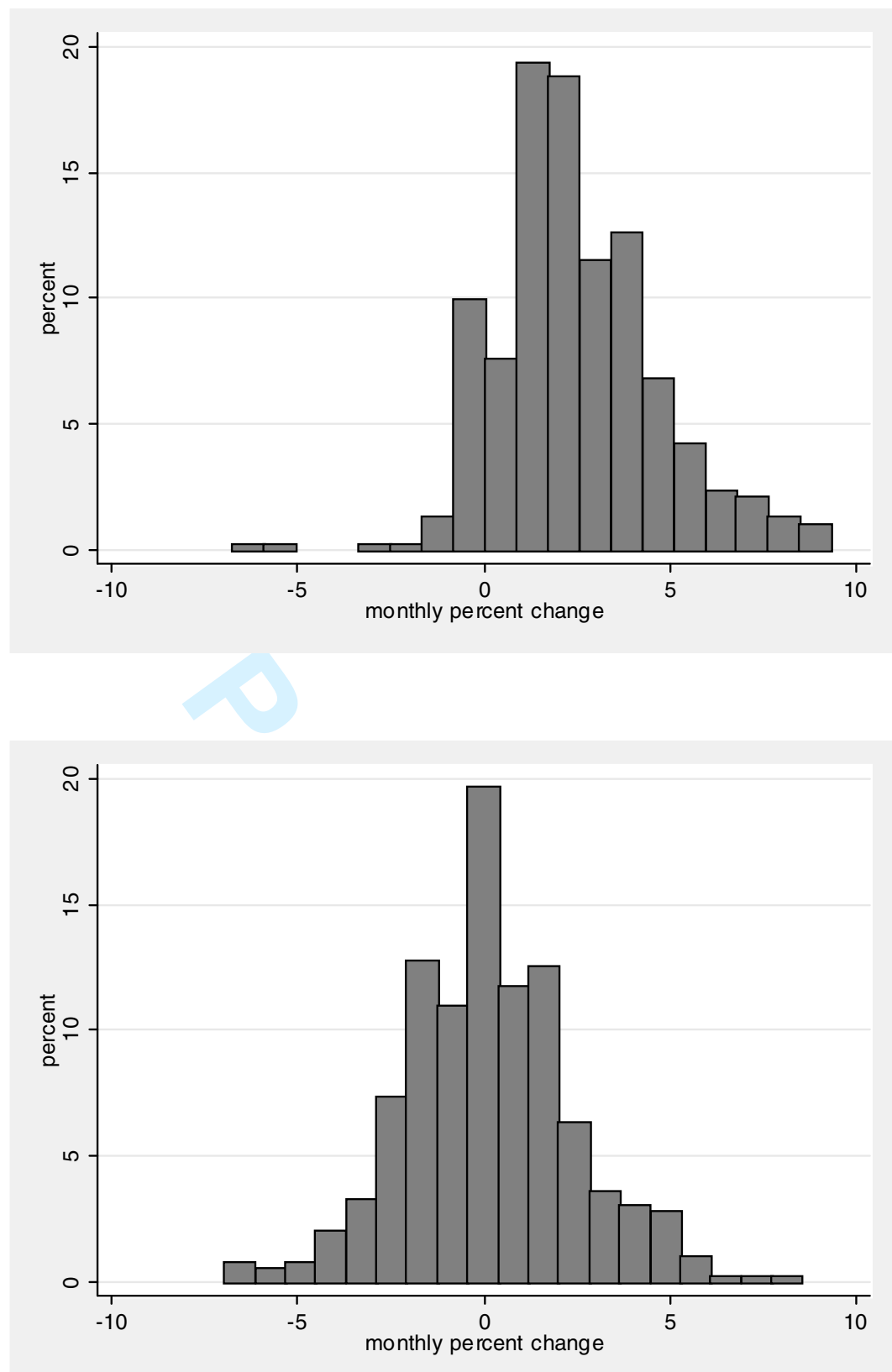
Figure 3. Foreign Reserves, Gross and Net of liabilities towards the IMF (billion of US Dollars), Italy 1970-1980 (upper panel) and Argentina 1980-2002 (lower panel)
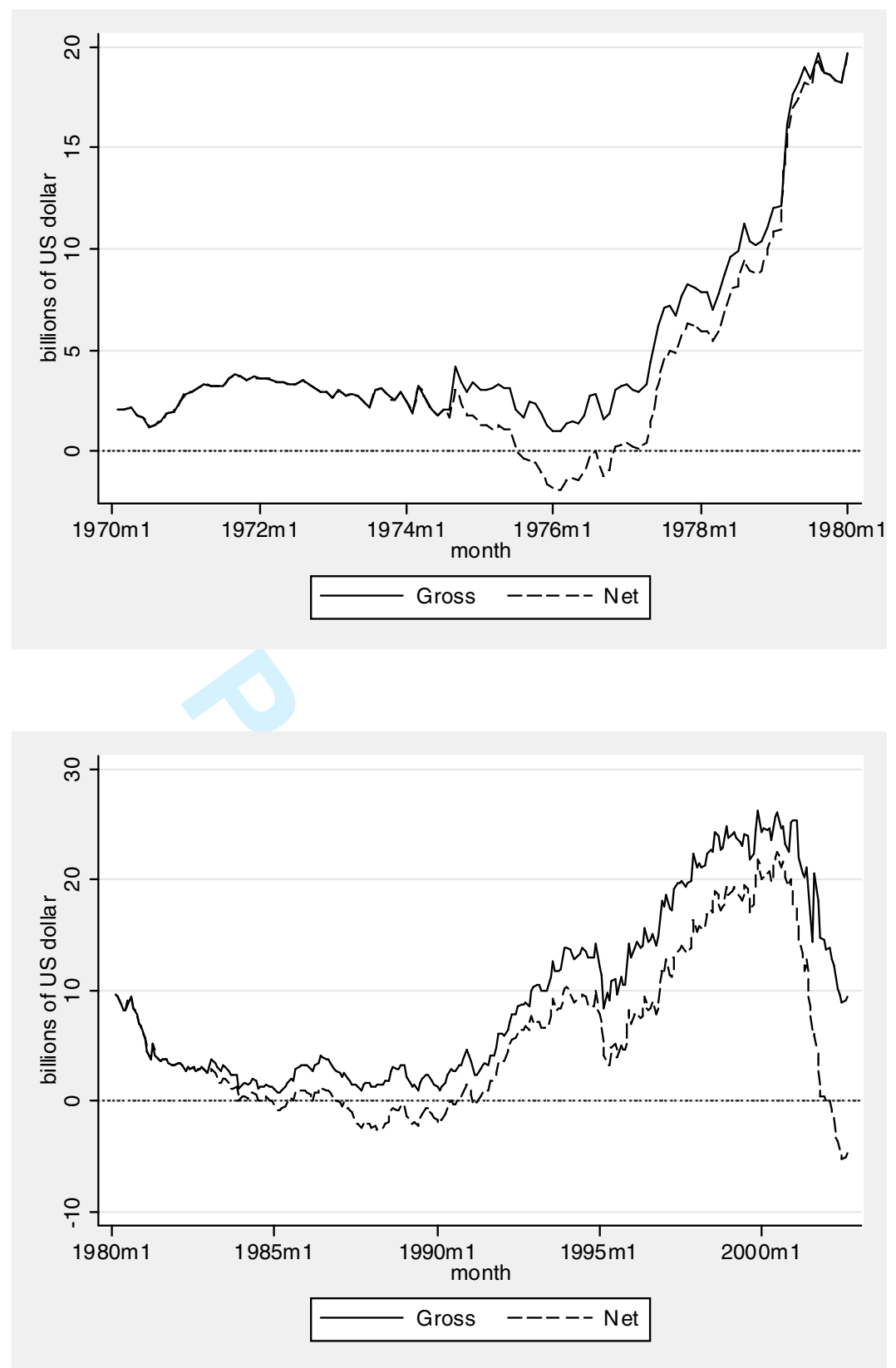
Table 1. Standard deviations of monthly nominal exchange rate returns:

Ratios of the values obtained via a logarithmic approximation to those obtained with the exact formula.

\begin{tabular}{lclc} 
& ratio (percent) & ratio (percent) \\
Developed countries & $\mathbf{9 9 . 5 8}$ & Emerging countries & $\mathbf{7 1 . 5 6}$ \\
\hline Denmark & 100.00 & Argentina & 60.60 \\
Finland & 99.16 & Chile & 44.81 \\
France & 99.23 & Colombia & 99.34 \\
Germany & 100.37 & Mexico & 85.74 \\
Italy & 99.19 & Peru & 37.34 \\
Netherlands & 100.00 & Uruguay & 36.59 \\
Spain & 98.80 & Venezuela & 69.99 \\
Sweden & 98.35 & Indonesia & 82.96 \\
United Kingdom & 99.59 & Malaysia & 98.52 \\
Canada & 100.00 & Philippines & 88.69 \\
Japan & 100.72 & Singapore & 100.00 \\
& & South Korea & 89.37 \\
& & Thailand & 96.51 \\
& & Turkey & 81.94
\end{tabular}

Note: We report averages by group of countries (Developed, respectively, Emerging), as a synthetic reference. 
Table 2. Divergence index $\operatorname{Div}_{\mathrm{i}, \mathrm{j}}$ across specifications of the EMP index

\begin{tabular}{|c|c|c|c|}
\hline & $\begin{array}{c}\text { Exchange Rate } \\
\text { (Log vs. Exact } \\
\text { Formula) }\end{array}$ & $\begin{array}{c}\text { Reserves } \\
\text { (Gross vs. Net) }\end{array}$ & $\begin{array}{c}\text { Weights } \\
\text { (Constant vs. } \\
\text { Time-varying) }\end{array}$ \\
\hline Developed countries & 0.01 & 0.01 & 0.24 \\
\hline Denmark & 0.00 & 0.00 & 0.25 \\
\hline Finland & 0.00 & 0.00 & 0.14 \\
\hline France & 0.00 & 0.00 & 0.21 \\
\hline Germany & 0.00 & 0.00 & 0.25 \\
\hline Italy & 0.00 & 0.00 & 0.30 \\
\hline Netherlands & 0.00 & 0.00 & 0.23 \\
\hline Spain & 0.06 & 0.00 & 0.16 \\
\hline Sweden & 0.00 & 0.00 & 0.44 \\
\hline United Kingdom & 0.03 & 0.07 & 0.27 \\
\hline Canada & 0.00 & 0.00 & 0.14 \\
\hline Japan & 0.00 & 0.00 & 0.16 \\
\hline Emerging countries & 0.10 & 0.16 & 0.34 \\
\hline Argentina & 0.20 & 0.38 & 0.38 \\
\hline Chile & 0.38 & 0.14 & 0.59 \\
\hline Colombia & 0.07 & 0.00 & 0.19 \\
\hline Mexico & 0.05 & 0.28 & 0.25 \\
\hline Peru & 0.33 & 0.31 & 0.76 \\
\hline Uruguay & 0.31 & 0.23 & 0.41 \\
\hline Venezuela & 0.00 & 0.25 & 0.20 \\
\hline Indonesia & 0.13 & 0.13 & 0.13 \\
\hline Malaysia & 0.00 & 0.00 & 0.33 \\
\hline Philippines & 0.00 & 0.05 & 0.15 \\
\hline Singapore & 0.05 & 0.00 & 0.29 \\
\hline South Korea & 0.06 & 0.16 & 0.38 \\
\hline Thailand & 0.00 & 0.18 & 0.18 \\
\hline Turkey & 0.00 & 0.06 & 0.22 \\
\hline
\end{tabular}

Note: We report averages by group of countries (Developed, respectively, Emerging), as a synthetic reference. 
Table 3 Percent of episodes identified as crisis as a function of the threshold $\tau$

\begin{tabular}{|c|c|c|c|c|}
\hline \multirow[b]{3}{*}{$\begin{array}{l}\text { Reference value when the } \\
\text { distribution of the EMP } \\
\text { index is assumed normal. }\end{array}$} & \multicolumn{4}{|c|}{ Values of the threshold $\tau$} \\
\hline & 1.5 & 2.0 & 2.5 & 3.0 \\
\hline & 6.68 & 2.28 & 0.62 & 0.13 \\
\hline \multirow[b]{2}{*}{ Developed countries } & \multicolumn{4}{|c|}{ Percent of episodes identified as crisis } \\
\hline & 5.88 & 3.48 & 2.10 & 1.29 \\
\hline Denmark & 7.78 & 4.90 & 2.59 & 0.86 \\
\hline Finland & 5.76 & 3.46 & 2.31 & 1.44 \\
\hline France & 5.76 & 3.46 & 2.31 & 1.73 \\
\hline Germany & 6.34 & 2.02 & 0.86 & 0.58 \\
\hline Italy & 5.19 & 4.03 & 2.59 & 2.31 \\
\hline Netherlands & 5.76 & 4.03 & 2.31 & 1.73 \\
\hline Spain & 4.90 & 3.46 & 2.59 & 1.73 \\
\hline Sweden & 5.19 & 2.88 & 2.02 & 2.02 \\
\hline United Kingdom & 7.34 & 3.54 & 1.52 & 0.51 \\
\hline Canada & 6.33 & 3.80 & 2.53 & 1.27 \\
\hline Japan & 4.30 & 2.78 & 1.52 & 0.25 \\
\hline Emerging countries & 3.92 & 2.64 & 1.84 & 1.48 \\
\hline Argentina & 5.06 & 3.80 & 2.53 & 2.53 \\
\hline Chile & 3.04 & 1.77 & 1.52 & 1.01 \\
\hline Colombia & 3.54 & 2.03 & 1.27 & 1.01 \\
\hline Mexico & 5.57 & 3.04 & 2.78 & 2.03 \\
\hline Peru & 3.04 & 2.03 & 1.27 & 1.27 \\
\hline Uruguay & 3.29 & 2.03 & 0.76 & 0.51 \\
\hline Venezuela & 3.29 & 3.04 & 2.28 & 2.03 \\
\hline Indonesia & 3.54 & 2.78 & 2.03 & 1.27 \\
\hline Malaysia & 4.56 & 3.04 & 2.28 & 2.03 \\
\hline Philippines & 4.56 & 2.53 & 2.28 & 1.77 \\
\hline Singapore & 4.56 & 3.54 & 1.77 & 1.01 \\
\hline South Korea & 4.05 & 3.04 & 1.52 & 1.27 \\
\hline Thailand & 2.78 & 1.52 & 1.27 & 1.27 \\
\hline Turkey & 4.05 & 2.78 & 2.28 & 1.77 \\
\hline
\end{tabular}

Note: We report averages by group of countries (Developed, respectively, Emerging), as a synthetic reference. 
Table 4. $95^{\text {th }}$ percentiles of the standardized EMP index with different specifications

\begin{tabular}{|c|c|c|c|c|c|c|c|c|}
\hline \multirow{4}{*}{$\begin{array}{r}\text { Exchange rate } \\
\text { Weights } \\
\text { Reserves }\end{array}$} & \multicolumn{4}{|c|}{ Logarithmic approximation } & \multicolumn{4}{|c|}{ Exact formula } \\
\hline & \multicolumn{2}{|c|}{ Constant } & \multicolumn{2}{|c|}{ Time-varying } & \multicolumn{2}{|c|}{ Constant } & \multicolumn{2}{|c|}{ Time-varying } \\
\hline & Gross & Net & Gross & $\mathrm{Net}$ & Gross & $\mathrm{Net}$ & Gross & $\mathrm{Net}$ \\
\hline & \\
\hline Denmark & 1.98 & 1.98 & 1.91 & 1.91 & 1.98 & 1.98 & 1.90 & 1.90 \\
\hline Finland & 1.56 & 1.58 & 1.64 & 1.64 & 1.57 & 1.57 & 1.63 & 1.63 \\
\hline France & 1.53 & 1.53 & 1.71 & 1.71 & 1.54 & 1.54 & 1.71 & 1.71 \\
\hline Germany & 1.53 & 1.53 & 1.63 & 1.63 & 1.55 & 1.55 & 1.64 & 1.64 \\
\hline Italy & 1.53 & 1.52 & 1.70 & 1.70 & 1.51 & 1.51 & 1.70 & 1.70 \\
\hline Netherlands & 1.64 & 1.64 & 1.53 & 1.53 & 1.64 & 1.64 & 1.53 & 1.53 \\
\hline Spain & 1.44 & 1.47 & 1.52 & 1.52 & 1.47 & 1.47 & 1.50 & 1.50 \\
\hline Sweden & 1.53 & 1.53 & 1.71 & 1.71 & 1.52 & 1.52 & 1.70 & 1.70 \\
\hline United Kingdom & 1.82 & 1.82 & 1.66 & 1.66 & 1.84 & 1.84 & 1.67 & 1.67 \\
\hline Canada & 1.73 & 1.73 & 1.84 & 1.84 & 1.73 & 1.73 & 1.84 & 1.84 \\
\hline Japan & 1.38 & 1.38 & 1.46 & 1.46 & 1.39 & 1.39 & 1.47 & 1.47 \\
\hline \multicolumn{9}{|l|}{ Emerging countries } \\
\hline Argentina & 1.53 & 1.44 & 1.64 & 1.47 & 1.25 & 1.43 & 1.30 & 1.61 \\
\hline Chile & 1.25 & 1.30 & 1.38 & 1.48 & 1.20 & 1.22 & 1.04 & 1.05 \\
\hline Colombia & 1.32 & 1.32 & 1.28 & 1.28 & 1.32 & 1.32 & 1.32 & 1.32 \\
\hline Mexico & 1.63 & 1.58 & 1.66 & 1.55 & 1.58 & 1.48 & 1.60 & 1.49 \\
\hline Peru & 1.24 & 1.32 & 1.13 & 1.43 & 0.94 & 1.10 & 0.92 & 1.45 \\
\hline Uruguay & 1.26 & 1.08 & 1.29 & 1.30 & 1.19 & 1.05 & 1.27 & 1.28 \\
\hline Venezuela & 1.27 & 1.28 & 1.27 & 1.22 & 1.22 & 1.18 & 1.23 & 1.14 \\
\hline Indonesia & 1.24 & 1.20 & 1.25 & 1.05 & 1.21 & 1.07 & 1.25 & 1.05 \\
\hline Malaysia & 1.41 & 1.41 & 1.46 & 1.46 & 1.41 & 1.40 & 1.46 & 1.46 \\
\hline Philippines & 1.38 & 1.43 & 1.46 & 1.46 & 1.39 & 1.44 & 1.40 & 1.45 \\
\hline Singapore & 1.49 & 1.49 & 1.42 & 1.42 & 1.49 & 1.49 & 1.42 & 1.42 \\
\hline South Korea & 1.32 & 1.48 & 1.16 & 1.35 & 1.30 & 1.44 & 1.18 & 1.39 \\
\hline Thailand & 1.11 & 1.13 & 1.16 & 1.04 & 1.10 & 1.11 & 1.14 & 1.04 \\
\hline Turkey & 1.39 & 1.40 & 1.25 & 1.29 & 1.28 & 1.29 & 1.19 & 1.27 \\
\hline
\end{tabular}

Notes: the different columns report the $95^{\text {th }}$ percentile of the standardized EMP index according to three different choices in the construction of the index: logarithmic approximation versus exact formula; constant versus time-varying weights; gross versus net reserves. By row, the lowest and the highest values across the eight specifications for each country are reported in Boldface and Boldface Italics, respectively. 
Table 5. $99^{\text {th }}$ percentiles of the standardized EMP index with different specifications

\begin{tabular}{|c|c|c|c|c|c|c|c|c|}
\hline \multirow{3}{*}{$\begin{array}{r}\text { Exchange rate } \\
\text { Weights } \\
\text { Reserves }\end{array}$} & \multicolumn{4}{|c|}{ Logarithmic approximation } & \multicolumn{4}{|c|}{ Exact formula } \\
\hline & \multicolumn{2}{|c|}{ Constant } & \multicolumn{2}{|c|}{ Time-varying } & \multicolumn{2}{|c|}{ Constant } & \multicolumn{2}{|c|}{ Time-varying } \\
\hline & Gross & Net & Gross & Net & Gross & Net & Gross & $\mathrm{Net}$ \\
\hline \multicolumn{9}{|l|}{ Developed countries } \\
\hline Denmark & 3.00 & 3.00 & 3.10 & 3.10 & 3.05 & 3.05 & 3.13 & 3.13 \\
\hline Finland & 3.75 & 3.75 & 3.83 & 3.83 & 3.76 & 3.76 & 3.84 & 3.84 \\
\hline France & 3.65 & 3.65 & 3.66 & 3.66 & 3.66 & 3.66 & 3.69 & 3.69 \\
\hline Germany & 2.36 & 2.36 & 2.71 & 2.71 & 2.41 & 2.41 & 2.75 & 2.75 \\
\hline Italy & 4.36 & 4.38 & 3.72 & 3.72 & 4.40 & 4.42 & 3.83 & 3.72 \\
\hline Netherlands & 3.91 & 3.91 & 3.28 & 3.28 & 3.91 & 3.91 & 3.28 & 3.28 \\
\hline Spain & 3.30 & 3.29 & 3.29 & 3.31 & 3.36 & 3.32 & 3.32 & 3.33 \\
\hline Sweden & 4.10 & 4.10 & 3.51 & 3.51 & 4.17 & 4.17 & 3.66 & 3.66 \\
\hline United Kingdom & 2.72 & 2.76 & 3.14 & 3.14 & 2.72 & 2.75 & 3.13 & 3.13 \\
\hline Canada & 3.21 & 3.21 & 3.40 & 3.40 & 3.23 & 3.23 & 3.40 & 3.40 \\
\hline Japan & 2.76 & 2.76 & 2.75 & 2.75 & 2.82 & 2.82 & 2.82 & 2.82 \\
\hline \multicolumn{9}{|l|}{ Emerging countries } \\
\hline Argentina & 4.79 & 5.26 & 4.75 & 5.13 & 5.64 & 5.28 & 5.59 & 5.23 \\
\hline Chile & 3.54 & 3.22 & 3.40 & 3.50 & 3.07 & 3.04 & 4.39 & 4.47 \\
\hline Colombia & 3.11 & 3.11 & 2.96 & 2.96 & 3.16 & 3.16 & 3.06 & 3.06 \\
\hline Mexico & 4.53 & 4.82 & 4.31 & 4.70 & 4.78 & 4.95 & 4.33 & 4.93 \\
\hline Peru & 4.06 & 4.93 & 3.37 & 4.03 & 3.39 & 4.29 & 2.76 & 3.85 \\
\hline Uruguay & 2.37 & 2.45 & 2.47 & 3.07 & 2.27 & 2.40 & 2.52 & 2.93 \\
\hline Venezuela & 4.67 & 4.45 & 4.68 & 4.49 & 4.31 & 4.08 & 4.45 & 4.25 \\
\hline Indonesia & 3.37 & 3.51 & 3.74 & 3.85 & 3.32 & 3.44 & 3.64 & 3.74 \\
\hline Malaysia & 3.67 & 3.66 & 4.09 & 4.09 & 3.74 & 3.73 & 4.20 & 4.20 \\
\hline Philippines & 4.07 & 3.79 & 4.28 & 4.06 & 4.06 & 3.75 & 4.40 & 4.19 \\
\hline Singapore & 3.11 & 3.11 & 2.81 & 2.81 & 3.12 & 3.12 & 2.82 & 2.82 \\
\hline South Korea & 3.18 & 3.50 & 3.13 & 3.72 & 3.06 & 3.39 & 3.07 & 3.68 \\
\hline Thailand & 4.13 & 4.04 & 4.04 & 3.94 & 4.24 & 4.15 & 4.15 & 4.05 \\
\hline Turkey & 4.59 & 4.50 & 3.92 & 3.55 & 4.51 & 4.52 & 3.88 & 3.59 \\
\hline
\end{tabular}

Notes: the different columns report the $99^{\text {th }}$ percentile of the standardized EMP index according to three different choices in the construction of the index: logarithmic approximation versus exact formula; constant versus time-varying weights; gross versus net reserves. By row, the lowest and the highest values across the eight specifications for each country are reported in Boldface and Boldface Italics, respectively. 
Table 6. Periods classified as crisis for six Asian countries according to the reference country chosen Periods classified as crisis when the reference

\begin{tabular}{lcccc} 
& \multicolumn{4}{c}{ country is } \\
\cline { 2 - 5 } & $\begin{array}{c}\text { Both the US } \\
\text { and Japan }\end{array}$ & Just the US & Just Japan & Div $_{\mathrm{i}, \mathrm{j}}$ \\
\cline { 2 - 5 } Indonesia & 13 & 3 & 0 & 0.19 \\
Malaysia & 12 & 6 & 16 & 0.65 \\
Philippines & 16 & 2 & 9 & 0.41 \\
Singapore & 5 & 13 & 16 & 0.85 \\
Thailand & 8 & 3 & 6 & 0.53 \\
South Korea & 12 & 4 & 6 & 0.45
\end{tabular}

